\title{
Medical Device Regulation and current challenges for the implementation of new technologies
}

\begin{abstract}
The European Parliament and the European Council on May 26, 2017 decided to introduce the new regulatory framework for medical devices. The transitional period of the so called Medical Device Regulation (EU 2017/745, MDR) should end on May 26, 2020. Currently the European Commission is working on a proposal to postpone the application for one year to relieve pressure from all stakeholders allowing them to fully focus on priorities related to the coronavirus crisis. From this date or most likely from May 26, 2021, manufacturers must present a CE-certificate according to the new MDR requirements not only for novel medical devices, but also for approved medical devices which are already on the market. The MDR will significantly complicate the process of bringing medical devices into market due to the increased requirements for the CE-certification process, particularly concerning increased documentation effort.
\end{abstract}

This involves a risk for the translation of innovative products due to an overload of the overall system (manufacturers, Notified Bodies, experts) and might lead to shrinkage of the product range of existing products. Thankfully, adaption of transitional periods, special regulations, extensions of deadlines and most probably postponement of the MDR application date will ensure that there will be no gaps in medical supply that endanger patients. Establishing and keeping the relevant regulatory expertise up to date and devoting the necessary financial, time and human resources that is the biggest immediate challenge the medium-sized medical technology sector is facing in the near future.

The current article, written about one month before the ini-

\footnotetext{
*Corresponding author: Sebastian Kaule: Institute for Implant Technology and Biomaterials e.V., Rostock-Warnemünde, Germany, e-mail: sebastian.kaule@uni-rostock.de;

Andrea Bock, Ariane Dierke, Stefan Siewert, Klaus-Peter Schmitz, Michael Stiehm: Institute for ImplantTechnology and Biomaterials e.V., Rostock-Warnemünde, Germany | Ernst Klar MD, FACS, Matthias Leuchter: Department of Surgery, University Medical Center Rostock, Germany | Thomas Lenarz MD, Department of Otolaryngology, Hannover Medical University | Marek Zygmunt MD: Clinic and Polyclinic for Gynaecology and Obstetrics, University Medical Center Greifswald, Germany | Wolfram Schmidt, Niels Grabow, Klaus-Peter Schmitz: Institute for Biomedical Engineering, University Medical Center Rostock, Germany
}

tially expected end of the first transition period on May 26, 2020, summarized the main aspects of the current state of MDR implementation with respect to regulatory novelties, the current legal basis in Germany, transition periods and changes in the requirements of CE-certification relevant technical documentation.

Furthermore, challenges for existing and innovative medical devices were shortly discussed using a new stent based therapy of the proximal Fallopian tubal stenosis and transcatheter aortic valve implantation as two examples.

Keywords: medical device regulation, CE-certification, regulatory affairs.

https://doi.org/10.1515/cdbme-2020-3086

\section{Introduction}

During the last decades medical device technology evolved with respect to innovation and complexity. As an effect about 500,000 different medical devices are certified with the highly regarded CE-mark [1]. Additionally, an increase considering invasiveness and functional complexity of the devices is recognizable. Keeping the demography in mind, probably every human being will get in contact with at least one medical device during their lifetime.

As a result, the European Union (EU) in 2017 initiated and implemented the Medical Device Regulation (EU 2017/745, MDR) aiming for an essential increase of medical device safety and efficacy. After the three-year transition period the MDR will replace the previous certification directives on medical devices (93/42/EEC, MDD) and on active implants (90/385/EEC) on May 26, 2020 [2].

From this date, medical device manufacturers must present a CE-certificate according to the new MDR requirements not only for new medical devices placed on the market, but also for already approved and certified medical devices.

\section{Regulatory Novelties}

The focus of the amended certification directive is to increase patient safety by means of a wide variety of security mechanisms. Based on a new classification system, which particu- 
larly upgrades implants and medical software, higher demands are placed with regard to clinical data [3].

The aim of clinical evaluation is to prove safety and performance of a medical device and the legitimation of the benefit-risk ratio. In the future, manufacturers will have to submit significantly more clinical data of their own medical devices for MDR-compliant clinical evaluation than it is currently the case [3].

After bringing a product to market, continuous postmarket surveillance throughout the entire product life cycle is mandatory. Stricter vigilance mechanisms are intended to detect conspicuous features, especially in product series, at an early stage. For this purpose, register studies of professional associations are included and promoted on a legal basis [3].

During the initial phase of MDR, Notified Bodies will become the real bottleneck. The recertification of existing products represents a considerable additional burden with the danger of insufficient residual capacity for the translation of innovative products. The National Working Group for the Implementation of MDR in Germany (NAKI), in interaction with the Federal Ministry of Health (BMG), optimised essential points for the national implementation [3]. Several challenges in MDR-implementation still need to be addressed [3]:

(i) National legal basis,

(ii) Higher classification of existing products,

(iii) Recertification of products on the market,

(iv) Lack of capacity of Notified Bodies,

(v) Lack of experts for the Scrutiny procedure,

(vi) Product registration in case of EUDAMED delay,

(vii) New regulations for Post-market surveillance.

\subsection{Current legal basis in Germany}

The legal basis in Germany was built on two different, sequential laws the Medical Devices Adaptation Act-EU (MPAnpG-EU) and the Medical Devices Implementation Act (MPDG) [4]. The MPAnpG-EU was passed by the Federal Cabinet on November 6, 2019 and in an amended form by the Bundestag on March 5, 2020. Article 1 of this MPAnpGEU describes the MPDG and the following articles describe further legislative changes. The MPDG is intended to replace the Medical Devices Act (MPG) and will thus become binding in Germany for all manufacturers and operators of medical devices and for other stakeholders [4].

The detailed description of the legal changes is not part of this short contribution and would lead too far but in short, the following points can be summarized regarding the change from MPG to MPDG [4]:

- Overall scope is growing (69 paragraphs in MPDG to 44 paragraphs in MPG),

- Structure of the document remains similar,
- No higher penalties, but more reasons for legal punishment,

- Safety officers deleted but medical device consultants remain important,

- More requirements for clinical trials/performance evaluation,

- Extended responsibilities of Federal Institute for Drugs and Medical Devices (BfArM) and Paul Ehrlich Institute (PEI), references to German Institute for Medical Documentation and Information removed.

The legal basis for the implementation of the MDR has been adopted on time in Germany. Essential points that must be taken into account for a practicable implementation have been summarized in corresponding statements of the Working group of the medical scientific societies (AWMF) $[5,6]$.

\subsection{Transition periods}

The main question for medical device manufacturers regarding transition periods is usually limited to the aspect of how long a product may be placed on the market. Article 120, MDR, regulates transitional provisions including the different periods. The following aspects need to be distinguished when searching for the right transition period:

- Placing new products on the market and "legacy" products,

- Provision and commissioning of products,

- „Person Responsible for Regulatory Compliance“ (PRRC),

- Post-Market Surveillance,

- Vigilance,

- Quality management system,

- Unique device identification (UDI) and EUDAMEDdatabase,

- Clinical trials [7].

Some of these aspects and the related transition periods are given in Figure 1. Nevertheless, medical device manufacturers need to find their individual pathway through the jungle of periods and steps.

\begin{tabular}{|ll|}
\hline 26.05. 2020 & $\begin{array}{l}\text { Device certification according to MDR } \\
\text { MDD device certifications remain valid } \\
\text { No further MDD certification }\end{array}$ \\
\hline 06.05.2021 & $\begin{array}{l}\text { UDI-labeling for implantable class III } \\
\text { devices (reusable 26.05.2023) }\end{array}$ \\
\hline 2022 & What about EUDAMED? \\
\hline 26.05 .2023 & UDI-labeling for class Ila and IIb devices \\
\hline 26.05 .2024 & $\begin{array}{l}\text { MDD certificates become invalid } \\
\text { Clearance sale of MDD certified devices }\end{array}$ \\
\hline 26.05 .2025 & $\begin{array}{l}\text { Distribution-stop of MDD certified devices } \\
\text { UDI-labeling for class I devices }\end{array}$ \\
\hline
\end{tabular}

Figure 1: Selected transition periods in MDR [7] 


\subsection{Changes in requirements of technical documentation}

The requirements for the content of the technical documentation for medical device certification, is one of the main aspects for changes in the MDR. Some of these changes in comparison to MDD are summarized in Table 1. The extensive documentation effort can only be managed using digitalization solutions, e.g. for tracking of medical devices or for efficient document management.

Table 1: Overview of requirement changes from MDD to MDR regarding the essential requirements of a medical device [4].

\begin{tabular}{lcc}
\hline Requirement & MDR & MDD \\
\hline Device description & & \\
- product and trade name & $\mathrm{X}$ & $(\mathrm{X})$ \\
- common specifications & $\mathrm{X}$ & $\mathrm{X}$ \\
- classification and justification & $\mathrm{X}$ & $(\mathrm{X})$ \\
- configurations & $\mathrm{X}$ & - \\
- photos & & \\
Identification & $\mathrm{X}$ & - \\
- UDI DI & & \\
Labelling & $\mathrm{X}$ & - \\
- Brochures, catalogues & $\mathrm{X}$ & $\mathrm{X}$ \\
- Instructions for use & $\mathrm{X}$ & $\mathrm{X}$ \\
- Labels & $\mathrm{X}$ & $\mathrm{X}$ \\
- packaging & & \\
Intended Use & $\mathrm{X}$ & - \\
- Indications + contraindications & $\mathrm{X}$ & - \\
- Patient population & $\mathrm{X}$ & - \\
- Intended users & $\mathrm{X}$ & $(\mathrm{X})$ \\
- Intended use case & $\mathrm{X}$ & - \\
- Accessories & $\mathrm{X}$ & $(\mathrm{X})$ \\
- Interaction with other products & & \\
Physical principle & $\mathrm{X}$ & - \\
- Description of new features & $\mathrm{X}$ & - \\
- Overview of similar products & $\mathrm{X}$ & - \\
- Overview of predecessor products & & \\
Structure & $\mathrm{X}$ & - \\
- Essential functions & $\mathrm{X}$ & - \\
- Technical specifications & - & $\mathrm{X}$ \\
- Calculations & $\mathrm{X}$ & $\mathrm{X}$ \\
- Parts, components, compositions & $\mathrm{X}$ & $\mathrm{X}$ \\
- Drawings, diagrams, explanations & $\mathrm{X}$ & - \\
- Description of materials & & \\
Production & & \\
- Development and production phases incl. vali- & & \\
- dation of process and tools, testing & $\mathrm{X}$ & $\mathrm{X}$ \\
- Indication of all locations incl. suppliers and & & \\
$\quad$ subcontractors involved in development and & & \\
production & $\mathrm{X}$ & - \\
Risk Management & & \\
- Risk-benefit analysis & & \\
\hline
\end{tabular}

Requirement

MDR MDD

- Risk management plan

- Risk acceptance

- Risk analysis

- Risk control measures

- Results of risk management and measures

$X \quad-$

$x \quad x$

$X \quad(X)$

$x \quad x$

Data from research and development

- Results of in vitro and preclinical tests (e.g. X laboratory, simulation, animal experiments) incl. description of test design e.g. with reference to Biocompatibility, electrical safety, biological and toxic materials, software

- Clinical evaluation

$\mathrm{X} \quad \mathrm{X}$

\section{Challenges for existing and innovative medical devices}

When looking at MDR certification of medical devices there are actually two main perspectives to consider. On the one hand there are devices with clinical evidence and market history and on the other hand there are completely new technologies for which there are no concepts for a clinical investigation.

An example for such an innovative device is the stent based concepts for the therapy of proximal Fallopian tubal stenosis, see Figure 2. To accelerate the transfer of these new implant concepts into clinical application research institutes and manufacturers need to develop comprehensive overviews of approval-relevant tests and documentation. A key role is also played by identifying the clinical trials required for the medical device certification process.

Clinical trials for the

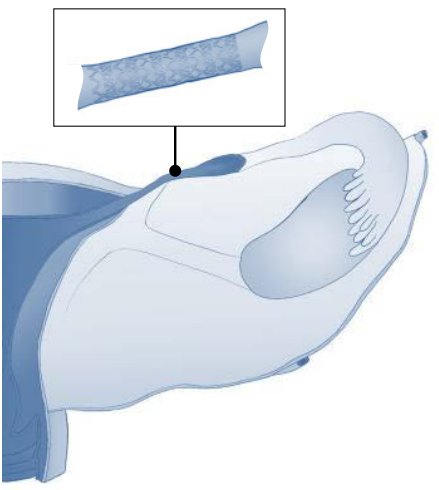

Figure 2: Concept of a stent based therapy of proximal Fallopian tubal stenosis. new implant concepts must be identified depending on the stage of their development. Special consideration must be given to the fulfilment of the basic safety and performance requirements when the product is used as intended, to the assessment of undesirable side effects and to the legitimation of the benefit-risk ratio according to MDR Art. 62 or Art. 82 .

One approach for the development of clinical study designs would be the development of graduated clinical test procedures according to the IDEAL-Recommendations [8].

Furthermore, a gradual market access should be established for new and innovative products. A possible option could be the implementation of tests for the devices under 
controlled conditions in suitably qualified clinical institutes, prior to general authorisation of the device. These institutions should test new medical devices within the scope of clinical trials and studies; collect the data obtained and submit them to the responsible Notified Bodies for evaluation. USA`s Food and Drug Administration (FDA) implemented an adequate procedure, the $510 \mathrm{k}$ premarket notification.

This could enable a controlled step-by-step proof of clinical effectiveness. In this way, medical technology innovations are made available to specific patient groups even before they are generally launched on the market.

The challenge for existing medical devices with a lot of clinical data and time on market, such as transcatheter aortic valve prostheses (see Figure 3) is their recertification in MDR-context.

For the recertification of products on the market, a central question needs to be answered: What is sufficient clinical data? In order to maintain functionality during MDR

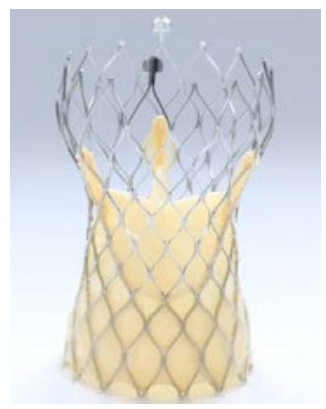

Figure 3: Transcatheter aortic valve prosthesis. implementation, the AWMF ad hoc commission has developed the following definition: There is sufficient proof of safety and benefit, if a product has been followed in a registry over a sufficient time without irregularities [5]. The definition of "sufficient time" is product-specific and must be defined by a group of experts. Recourse to existing registers of professional societies and the establishment of new registers will make the recertification of products feasible. The importance and structure of registries is also defined by the Implant Registry Act Germany.

Registries may be useful for collecting real-world clinical evidence concerning existing medical devices. They may also be a tool to examine rare adverse effects, subpopulations or for studying time durations which are not possible or feasible to study within a separate clinical investigation $[1,3]$.

\section{Conclusion}

Although the new regulation of medical device law at European level brings more safety for patients, it also leads to longer waiting periods for innovative products. Especially with respect to the tense situation concerning the Notified Bodies who have to master the immense amount of certification documents in the near future. Currently only eleven Notified Bodies are MDRcertified coming from 55 notified bodies in MDD.

The need for more detailed technical documentation and the accented responsibility of manufacturers and authorities results in a need for high-quality test procedures. Medical device manu- facturers fear drawbacks during the approval process, as it would be considerably more difficult to comply with the stricter requirements due to lower personnel capacities and financial resources. Independent and certified test laboratories may be suitable institutions to endorse manufacturers as well as Notified Bodies. Time will tell and show if all stakeholders can work together to lead MDR to the high level of safety that is intended.

\section{Author Statement}

Financial support by the European Regional Development Fund (ERDF) and the European Social Fund (ESF) within the collaborative research between economy and science of the state Mecklenburg-Vorpommern, by the Federal Ministry of Education and Research (BMBF) within RESPONSE "Partnership for Innovation in Implant Technology" and by the Federal Ministry for Economic Affairs and Energy (BMWi) within the "Mittelstand 4.0-Kompetenzzentrum Rostock" is gratefully acknowledged. Conflict of interest: Authors state no conflict of interest. Informed consent: Informed consent is not applicable. Ethical approval: The conducted research is not related to either human or animal use.

\section{References}

[1] Melvin T, Torre M, New medical device regulations: the regulator's view, EFORT Open Rev 2019; 4 DOI: 10.1302/20585241.4.180061.

[2] Regulation (EU) $2017 / 745$ of the European Parliament and of the Council of 5 April 2017 on medical devices, amending Directive 2001/83/EC, Regulation (EC) No 178/2002 and Regulation (EC) No 1223/2009 and repealing Council Directives 90/385/EEC and 93/42/EEC.

[3] Klar E and Leuchter M, Was gibt es Neues bei der Medical Device Regulation? Drohen Versorgungsengpässe durch neue Regularien? In: Jähne J, Königsrainer A, Südkamp N, Schröder W (Hrsg): Was gibt es Neues in der Chirurgie? Jahresband 2020, Kap. 8.3, ecomed Medizin, Landsberg [in print].

[4] Johner Institut $\mathrm{GmbH}$, blog post from March 04, 2020, https://www.johner-institut.de/blog/regulatory-affairs/medicaldevice-regulation-mdr-medizinprodukteverordnung/, last access: March 10, 2020.

[5] Arbeitsgemeinschaft der medizinisch wissenschaftlichen Fachgesellschaften. AWMF-Positionspapier der Ad-hoc-Kommission Nutzenbewertung von Medizinprodukten der AWMF zur Verbesserung der Patientensicherheit bei Zulassung und Monitoring von Medizinprodukten.

[6] Arbeitsgemeinschaft der medizinisch wissenschaftlichen Fachgesellschaften. AWMF-Stellungnahme: Kabinettsentwurf eines Gesetzes zur Anpassung des Medizinprodukterechts an die Verordnung (EU) 2017/745 und die Verordnung (EU) 2017/746 (Medizinprodukte-Anpassungsgesetz-EU).

[7] Nationalen Arbeitskreis zur Implementierung der neuen EUVerordnungen über Medizinprodukte (MDR) und In-vitroDiagnostika (IVDR) - Untergruppe 1 (Übergangsbestimmungen) „Fragen und Antworten Katalog“ zu den Übergangsbestimmungen der EU Medizinprodukte-Verordnung 2017/745 (MDR), 22.01.2018.

[8] McCulloch P, Altman D, Campbell WB, et al. No surgical innovation without evaluation: The IDEAL recommendations Lancet. 2009 Sep 26;374(9695):1105-12. doi: 10.1016/S01406736(09)61116-8 